\title{
Evaluation of thyroid dysfunction among type 2 diabetic patients
}

\author{
Pranav Kumar Raghuwanshi', Devendra Pratap Singh Rajput ${ }^{2}$, Bhupendra Kumar Ratre ${ }^{2}$, Roopesh Jain ${ }^{2}$, \\ Narmada Patel ${ }^{1}$, Sudeep Jain ${ }^{3}$
}

${ }^{1}$ Assistant Professor, Dept. of Medicine, L.N.Medical College, Bhopal, ${ }^{2}$ Associate Professor, Dept. of Medicine, L.N.Medical College, Bhopal, ${ }^{3}$ M.B.B.S. Student, L.N.Medical College, Bhopal

Background: Diabetes mellitus is a very common endocrinal disorders and incidence of thyroid dysfunction also rising in India and world over. Thyroid hormones directly control insulin secretion and insulin clearance. Diabetes also may affect the thyroid function to variable extent first at the level of hypothalamic control of TSH release and second at peripheral tissue by converting T4 to T3. Aims and Objectives: The present study was carried out aiming to evaluate thyroid dysfunction among type 2 diabetes mellitus patients. Material and Methods: Study included total 80 subjects. Thyroid dysfunction was evaluated by investigating the subjects for Total tri-iodo-thyronine (T3), Total thyroxine (T4) and thyroid stimulating hormone (TSH). Plasma glucose was estimated by- GOD-POD method and Thyroid profile was estimated by- CLIA (chemiluminescence immunoassay) system. Statistical analysis was performed using software statistical package for social sciences (SPSS) version 20, unpaired T test, Pearson's correlation. Results: In type 2 diabetic patients the prevalence of hypothyroidism and subclinical hypothyroidism was found to be $4(10.00 \%)$ and $6(15.00 \%)$ respectively, while the prevalence of subclinical hyperthyroidism and hyperthyroidism was found to be $0(0.0 \%)$ and $1(2.5 \%)$ respectively. In non diabetic healthy subjects the prevalence of hypothyroidism and subclinical hypothyroidism was found to be $1(2.5 \%)$ and $3(7.5 \%)$ respectively while the prevalence of subclinical hyperthyroidism and hyperthyroidism was found to be $0(0.0 \%)$ and $0(0.0 \%)$ respectively. Conclusion: The prevalence of thyroid dysfunction was found to be higher in type 2 diabetes mellitus subjects as compared to non-diabetic subjects.

Access this article online Website:

http://nepjol.info/index.php/AJMS

DOI: 10.3126/ajms.v6i3.10814

Key words: Type 2 diabetes mellitus, Hyperthyroidism, Hypothyroidism

\section{INTRODUCTION}

Diabetes mellitus is a common endocrine disorders rising in India and has reached approximately $20 \%$ in urban populations and approximately $10 \%$ in rural Population. ${ }^{1}$ On long term it is associated with vascular complications these are responsible for increased morbidity and mortality among diabetic subjects. ${ }^{2}$ New addition to these complications is the thyroid dysfunction which is indicated by the recent studies. ${ }^{3,4}$ The first report showing the association between diabetes and thyroid dysfunction was published in 1979. ${ }^{5,6}$ Since then a number of studies have estimated the prevalence of thyroid dysfunction among diabetes patients to be varying from
2.2 to $17 \%$, the most common disorder being subclinical hypothyroidism. ${ }^{7,8}$ However, few studies also estimated much higher prevalence of thyroid dysfunction in diabetes i.e., $31 \%$ and $46.5 \%$ respectively ${ }^{9,10}$ also not showed any significant correlation between FPG and thyroid profile parameters. Thyroid hormones directly control insulin secretion. In hypothyroidism, there is a reduction in glucose-induced insulin secretion by beta cells, and the response of beta cells to glucose or catecholamine is increased in hyperthyroidism due to increased beta cell mass. Moreover, insulin clearance is increased in thyrotoxicosis. ${ }^{11-13}$ Diabetes may affect the thyroid function to variable extent. Diabetes mellitus appears to influence thyroid function in two sites; first 
at the level of hypothalamic control of TSH release and second at peripheral tissue by converting T4 to T3. ${ }^{14,15}$ Unrecognized thyroid dysfunction not only worsens the metabolic control but also impede the management of diabetes. ${ }^{16}$ Studies also have suggested that type 2 diabetes mellitus patients with subclinical hypothyroidism are at risk of complications like nephropathy and cardiovascular events. ${ }^{17}$ The ability to diagnose and treat subclinical hypothyroidism in these patients may greatly enhance the quality of life. Hence there is need to detect such cases where hypothyroidism contributes to morbidity and where it is the cause for poor control of the associated conditions. The treatment of hypothyroidism helps in better control of other associated co-morbidities. So patients with diabetes need to be screened for thyroid dysfunction. Therefore, in present study association between thyroid dysfunction and Diabetes was assessed by correlating FPG and Thyroid profile.

\section{MATERIAL AND METHODS}

The present case control study entitled "Evaluation of thyroid Dysfunction among Type 2 diabetic patients" was conducted in department of medicine, L. N. Medical College \& Associated J. K. Hospital \& Research Centre Bhopal, (M.P.), India.

It included total 80 subjects equally divided between type 2 diabetes mellitus and non-diabetic healthy subjects. Age and sex matched controls were selected those who had no evidence of any disease clinically.

\section{Inclusion criteria}

1. Known case of type 2 Diabetes mellitus

2. Recently diagnosed case of type 2 Diabetes mellitus

The diagnosis of Diabetes Mellitus was based on the American Diabetes Association criteria for type 2 Diabetes Mellitus:

1. Fasting plasma glucose level higher than $126 \mathrm{mg} / \mathrm{dl}$ or

2. Plasma Glucose level exceeding $200 \mathrm{mg} / \mathrm{dl}$ at 2 hours in the $75 \mathrm{~g}$ oral glucose tolerance test or

3. Symptoms of Diabetes and Random Plasma Glucose $>200 \mathrm{mg} / \mathrm{dl}$

or

4. $\mathrm{HbA}_{1} \mathrm{C}>6.5 \%$.

\section{Exclusion criteria}

1. Patients taking drugs that influence the thyroid function.

2. Post partum women.

3. Acute illness that affects thyroid hormones status.

4. Patients who present with complain of fever, neck pain and viral infection (subacute thyroiditis)

Instruments used for assessment

Plasma glucose by GOD-POD method[semi autoanalyser (BTS-350), fully autoanalyser(BIOSYSTEM A-25)].

Thyroid Profile by CLIA (chemiluminescence immunoassay) system

\section{Laboratory Data}

Venous blood sample were withdrawn and assessed for thyroid function (T3, T4, and TSH) and for the glycaemic status (FPG).The following guidelines for detection of thyroid dysfunction were consider - 1) Normal - when T3, T4 and TSH were within the normal range. 2) Primary hypothyroidism - when TSH is more than $5.5 \mu \mathrm{IU} / \mathrm{L}$ and T3, T4 is less than the normal value. 3) Primary hyperthyroidism - when TSH is less than $0.2 \mu \mathrm{IU} / \mathrm{L}$ and T3, T4 is more than the normal values. 4) Subclinical hypothyroidism - when TSH is more than $5.5 \mu \mathrm{IU} / \mathrm{L}$ and T3, T4 is within the normal range. 5) Subclinical hyperthyroidism - when TSH is less than $0.2 \mu \mathrm{IU} / \mathrm{L}$ and $\mathrm{T} 3$, T4 are within the normal range.

\section{Statistical analysis}

Statistical analysis was performed using software statistical package for social sciences (SPSS) version 20, unpaired $T$ test, Pearson's correlation. P value of less than 0.05 was considered as statistically significant at $95 \%$ confidence intervals.

\section{RESULTS}

Table 1 Shows the age and sex distribution of diabetic and non-diabetic subjects. Type 2 diabetic subjects included 20 males of age group 31.9-56.5 years with mean age $44.2 \pm 12.3$ years, and 20 females of age group $32.5-52.8$ years with mean age of $42.7 \pm 10.12$ years. Non-diabetic healthy subjects also included 20 males of age group 34.6-57.6 years with mean age $46.1 \pm 11.5$ years, and 20 females of age group 33.0-54.6 years with mean age of $43.8 \pm 10.8$ years.

\begin{tabular}{|c|c|c|c|}
\hline Group & Sex & No & $\begin{array}{l}\text { Age range and } \\
\text { mean age in years }\end{array}$ \\
\hline \multirow[t]{2}{*}{ Type 2 DM subjects } & Male & 20 & $\begin{array}{c}31.9-56.5 \\
(44.2 \pm 12.3)\end{array}$ \\
\hline & Female & 20 & $\begin{array}{c}32.5-52.8 \\
(42.7 \pm 10.12)\end{array}$ \\
\hline \multirow[t]{2}{*}{ Non-diabetic subjects } & Male & 20 & $\begin{array}{c}34.6-57.6 \\
(46.1 \pm 11.5)\end{array}$ \\
\hline & Female & 20 & $\begin{array}{c}33.0-54.6 \\
(43.8 \pm 10.8)\end{array}$ \\
\hline
\end{tabular}

Asian Journal of Medical Sciences | May-Jun 2015 | Vol 6 | Issue 3 
Table 2 shows the comparison of levels of FPG and thyroid parameters in type 2 diabetes mellitus and non-diabetic healthy subjects. FPG were significantly higher in type 2 diabetes mellitus subjects as compared to the non-diabetic subjects. The serum levels of total T3 and total T4, were significantly lower in type 2 diabetes mellitus subjects as compared to the non-diabetic healthy subjects while level of serum TSH was significantly higher in type 2 diabetes mellitus subjects as compared to the non-diabetic healthy subjects.

Table 3 Presents the Type of thyroid disorders according to gender in type 2 diabetes mellitus and non-diabetic healthy control group.

Out of the $\mathbf{4 0}$ type 2 diabetes mellitus subjects studied

1. The prevalence of hypothyroidism and subclinical hypothyroidism was found to be $4(10.00 \%)$ and $6(15.00 \%)$ respectively.

2. The prevalence of subclinical hyperthyroidism and hyperthyroidism was found to be $0(0.0 \%)$ and $1(2.5 \%)$ respectively.

Out of the 40 non-diabetic healthy subjects studied

1. The prevalence of hypothyroidism and subclinical hypothyroidism was found to be $1(2.5 \%)$ and $3(7.5 \%)$ respectively.

2. The prevalence of subclinical hyperthyroidism and hyperthyroidism was found to be $0(0.0 \%)$ and $0(0.0 \%)$ respectively.

Table 3 also shows the prevalence of hypothyroidism was found to be more common in female $7(35 \%)$ as compared to male $3(15 \%)$.

\begin{tabular}{|c|c|c|c|c|}
\hline $\begin{array}{l}\text { Parameters } \\
\text { measured }\end{array}$ & $\begin{array}{l}\text { Normal } \\
\text { value }\end{array}$ & $\begin{array}{l}\text { Type } 2 \text { DM- } \\
\text { subjects }\end{array}$ & $\begin{array}{l}\text { Non-diabetics } \\
\text { healthy } \\
\text { subjects }\end{array}$ & p-value \\
\hline FPG (mg/dl) & $70-100$ & $158.95 \pm 30.0$ & $87.45 \pm 7.39$ & $<0.001$ \\
\hline T3 total (ng/dl) & $0.60-1.81$ & $0.87 \pm 0.34$ & $1.61 \pm 0.44$ & $<0.001$ \\
\hline $\mathrm{T} 4$ total $(\mu \mathrm{g} / \mathrm{dl})$ & $5.01-12.45$ & $7.29 \pm 2.14$ & $8.35 \pm 0.73$ & $<0.004$ \\
\hline TSH mIU/L & $0.35-5.50$ & $6.91 \pm 3.08$ & $3.93 \pm 1.82$ & $<0.001$ \\
\hline
\end{tabular}

This table also shows that hyperthyroidism was also found to be more common in female $1(5 \%)$ as compared to males $0(00.00 \%)$.

Table 4 shows the Pearson's correlation between FPG and Thyroid profile. Present study was found significant correlation between FPG and Total T3 and TSH levels. But FPG did not revealed significant correlation with Total T4.

\section{DISCUSSION}

The present case control study entitled "Evaluation of thyroid Dysfunction among Type 2 diabetic patients" was carried out at medicine department, L. N. Medical College, Bhopal \& Associated J. K. Hospital \& Research Center, Bhopal (M.P.), India.

It included total 80 subjects equally divided between type 2 diabetes mellitus and non-diabetic healthy subjects. Age and sex matched controls were selected those who had no evidence of any disease clinically.

The thyroid hormones are insulin antagonists that also potentiate the action of insulin indirectly. TRH synthesis decreases in diabetes mellitus. These facts could be responsible for the occurrences of low thyroid hormone levels in some diabetics. The level of TSH in our study was clinically significant in type 2 diabetes mellitus subjects than in non-diabetics healthy subjects. Results obtained from present study have shown that in type 2 diabetes mellitus, hypothyroidism is frequently observed. The results of present study were in accordance with the reports of Vinu vij et al, ${ }^{18}$ Gurjeet singh et al, ${ }^{19}$ Swamy RM et al, ${ }^{4}$ Suzuki et al, ${ }^{20}$ Celani et al, ${ }^{9}$ Demitrost L et al, ${ }^{21}$ Valerie Witting et al, ${ }^{22}$ who in separate study found altered thyroid profile in a diabetic patient. Present study found significant correlation between FPG and T3 \& TSH which needs further research for confirmation. Failure to recognize the presence of these abnormal thyroid hormone levels in diabetics may be a primary cause of poor management often encountered in some treated diabetics. Therefore, the present study was intended to evaluate the association between thyroid dysfunction with diabetic process and to assess the hyperglycemic effect by correlating fasting serum glucose and thyroid profile parameters. Thyroid

\begin{tabular}{|c|c|c|c|c|}
\hline $\begin{array}{l}\text { Distribution of subjects } \\
\text { according to gender }\end{array}$ & $\begin{array}{c}\text { Subclinical } \\
\text { Hypothyroidism }\end{array}$ & Hypothyroidism & $\begin{array}{c}\text { Subclinical } \\
\text { Hyperthyroidism }\end{array}$ & Hyperthyroidism \\
\hline Type 2 DM male $(\mathrm{N}=20)$ & 2 & 1 & 0 & 0 \\
\hline Type 2 DM female $(\mathrm{N}=20)$ & 4 & 3 & 0 & 1 \\
\hline Non diabetic male $(\mathrm{N}=20)$ & 1 & 0 & 0 & 0 \\
\hline Non diabetic female $(\mathrm{N}=20)$ & 2 & 1 & 0 & 0 \\
\hline
\end{tabular}




\begin{tabular}{|c|c|c|c|}
\hline Relationship between & r-values & p-value & Significance \\
\hline FPG vs T3 & 0.54 & 0.02 & $\mathrm{~S}$ \\
\hline FPG vs T4 & -0.156 & 0.17 & NS \\
\hline FPG vs TSH & 0.417 & $<0.01$ & $\mathrm{~S}$ \\
\hline
\end{tabular}

HS- highly significant ( $p<0.001)$, S- significant $(p<0.05)$, NS- not significant ( $p>0.05)$

function tests are especially recommended in patients with clinical suspicion and/or unexplained changes in diabetic metabolic control or serum cholesterol and weight gain. The treatment of hypothyroidism helps in better control of other associated co-morbidities. The ability to diagnose and treat subclinical hypothyroidism in these patients may greatly enhance the quality of life. Hence there is need to detect such cases where hypothyroidism contributes to morbidity and where it is the cause for poor control of the associated conditions.

\section{CONCLUSIONS}

The conclusions drawn from the present study are as follows:

1. The serum levels of total T3 and total T4 were significantly low, while serum TSH levels were higher in type 2 diabetes mellitus subjects as compared to the non-diabetic healthy subjects.

2. The prevalence of hypothyroidism and subclinical hypothyroidism was found to be higher in type 2 diabetes mellitus subjects as compared to non-diabetic subjects.

3. The prevalence of hyperthyroidism was found to be higher in type 2 diabetes mellitus subjects as compared to non-diabetic subjects while did not reveal any significant difference in the prevalence of subclinical hyperthyroidism.

4. The prevalence of hypothyroidism and hyperthyroidism was found to be more common in females as compared to males.

5. Present study found significant correlation between FPG and Total T3 and TSH levels. But FPG did not reveal significant correlation with Total T4.

We conclude that a systematic approach to thyroid testing in diabetic subjects is desirable; particularly in those patients whose associated conditions are difficult to manage. The treatment of hypothyroidism helps in better control of other associated conditions. The ability to diagnose and treat unsuspected hypothyroidism in these patients may greatly enhance the quality of life. Hence there is need to detect such cases where hypothyroidism contributes to morbidity and where it is the cause for poor control of the associated conditions.

\section{IMPLICATIONS}

1. It will be helpful in understanding the prevalence of Thyroid dysfunction in type 2 diabetes mellitus patients and also helpful in framing new policies and strategies to overcome it.

2. The study will serve as a valuable guideline for Physician to proceed for diagnosis and management of thyroid dysfunction in type 2 diabetes mellitus patients.

3. To initiate levels of prevention at the earliest possible stage and this is an important tool in control.

\section{ACKNOWLEDGEMENT}

We would like to cordially thank to all the patients and healthy control for participating in this study and to the department of Medicine and Biochemistry department of L. N. Medical College \& J. K. Hospital \& Research Center, Bhopal (M.P.), India for supporting this study and college authority for allowing to conduct the study.

\section{REFERENCES}

1. Ramachandran A and Snehalatha C. "Current scenario of diabetes in India". J Diabetes 2009; 1 (1):18-28.

2. Zargar AH, Wani Al, Masoodi SR, Laway BA and Bashir MI. "Mortality in diabetes mellitus data from a developing region of the world". Diabetes Res Clin Pract 1999; 43: 67-74.

3. Papazafiropoulou A. "Prevalence of thyroid dysfunction among greek Type 2 diabetic patients attending an outpatient clinic". Journal of Clinical Medicine Research 2010; 2 (2):75-78.

4. Swamy RM, Kumar N, Srinivasa K, Manjunath GN, Prasad Byrav DS and Venkatesh G. "Evaluation of hypothyroidism as a complication in Type 2 Diabetes Mellitus" Biomedical Research 2012; 23 (2): 170-172.

5. Feely $\mathrm{J}$ and Isles TE. "Screening for thyroid dysfunction in diabetics". Br Med J 1979; I (6179):1678.

6. Gray RS, Irvine WJ and Clarke BF. "Screening for thyroid dysfunction in diabetics". Br Med J 1979; 2 (6 202): 1439.

7. Perros $P, M c$ Crimmon RJ, Shaw $G$ and Frier BM. "Frequency of thyroid dysfunction in diabetics patients: value of annual screening". Diabet Med 1995; 12 (7): 622-627.

8. Smithson MJ. "Screening for thyroid dysfunction in a community population of diabetic patients". Diabet Med 1998; 15 (2):148-150.

9. Celani MF, Bonati ME and Stucci N. "Prevalence of abnormal thyrotropin concentrations measured by a sensitive assay in patients with Type 2 diabetes mellitus". Diabete Res 1994; 27(1):15-25.

10. Udoing CEJA, Udoh E and Etukudoh ME. "Evaluation of thyroid function in diabetes mellitus in Calabar, Nigeria" Indian J Clin Biochem 2007; 22:74-78.

11. Wang $C$. "The relationship between type 2 diabetes mellitus and related thyroid diseases". Journal of diabetes research 2013; 1-9.

12. Stanick'a S, Vondra K, Pelik'anov'a T, VIcek P, Hill M and Zamrazil V. "Insulin sensitivity and counter-regulatory hormones in hypothyroidism and during thyroid hormone replacement therapy," Clinical Chemistry and Laboratory Medicine 2005; 43(7):715-720. 
13. Mitrou P, Raptis SA, and Dimitriadis G. "Insulin action in hyperthyroidism: a focus on muscle and adipose tissue," Endocrine Reviews 2010; 31(5):663-679.

14. Vikhe VB, Kanitkar SA, Tamakuwala KK, Gaikwad AN, Kalyan M and Agarwal RR. "Thyroid dysfunction in patients with type 2 diabetes mellitus at tertiary care center". National Journal of medical research 2013; 3(4):377-380.

15. Shah SN. "Thyroid disease in diabetes mellitus". J Assoc Physicians India 2007; 32(12):1057-1059.

16. Duntas LH, Orgiazzi $\mathrm{J}$ and Brabant G. "The Interface between thyroid and diabetes mellitus". Clin Endcorinol (Oxf) 2011; 75(1):1-9.

17. Chen HS, Wu TE, Jap TS, Lu RA, Wang ML, Chen RL, et al. " Subclinical hypothyroidism is a risk factor for nephropathy and cardiovascular diseases in Type 2 diabetic patients". Diabet Med 2007; 24(12):1336-1344.
18. Vij V, Chitnis P and Gupta VK. "Evaluation of thyroid dysfunction among type II diabetic patients" IJPBS 2012; 2(4):150-155.

19. Singh G, Gupta V, Sharma AK and Gupta N, "Evaluation of Thyroid Dysfunction Among type 2 diabetic Punjabi Population" Advances in bioresearch 2011;2(2):3-9.

20. Suzuki J, Nanno M, Gemma R, Tanaka I, Taminato T and Yoshimi T. "The mechanism of thyroid hormone abnormalities in patients with diabetes mellitus". Nippon Niabunpi. Gakki Zasshi 1994; 7: 465-470.

21. Demitrost $L$ and Ranabir $S$. "Thyroid dysfunction in type 2 diabetes mellitus: A retrospective study" Indian Journal of Endocr Metab 2012; 16:s334-s335.

22. Valerie $\mathbf{W}$, Dominik B, Dilek $S$ and Klaus B. "Thyroid disease in insulin-treated patients with type 2 diabetes: a retrospective study". Thyroid Research Journal 2014;7(2):1-6.

\section{Authors Contribution:}

PKR - Concept, design of study, definition of intellectual content, literature search, clinical studies, statistical analysis, manuscript preparation; DPSR - definition of intellectual content, literature search, statistical analysis, manuscript preparation; BKR - definition of intellectual content, literature search, statistical analysis, manuscript revision; RJ - concept, design of study, definition of intellectual content, manuscript revision; NP - literature search, clinical studies, participated in data and sample collection, manuscript revision; SJ - literature search, clinical studies, participated in data and sample collection, manuscript revision.

Source of Support: Nil, Conflict of Interest: None declared. 